Article

\title{
The Fungus Metarhizium sp. BCC 4849 Is an Effective and Safe Mycoinsecticide for the Management of Spider Mites and Other Insect Pests
}

\author{
Rudsamee Wasuwan ${ }^{1}$, Natnapha Phosrithong ${ }^{1}$, Boonhiang Promdonkoy ${ }^{1}$, Duangjai Sangsrakru ${ }^{1}$, \\ Chutima Sonthirod ${ }^{1}$, Sithichoke Tangphatsornruang ${ }^{1} \mathbb{D}$, Somsak Likhitrattanapisal ${ }^{1}$, Supawadee Ingsriswang ${ }^{1}$, \\ Chettida Srisuksam ${ }^{1}$, Kewarin Klamchao ${ }^{1}$, Malinee Suksangpanomrung ${ }^{1}$, Thipmanee Hleepongpanich ${ }^{1}$, \\ Sareeya Reungpatthanaphong ${ }^{2}$, Morakot Tanticharoen ${ }^{3}$ and Alongkorn Amnuaykanjanasin ${ }^{1, *(D)}$
}

1 National Center for Genetic Engineering and Biotechnology, National Science and Technology Development Agency, Pathum Thani 12120, Thailand; rudsamee.was@biotec.or.th (R.W.); natnapha.pho@ncr.nstda.or.th (N.P.); boonhiang@biotec.or.th (B.P.); duangjai.san@nstda.or.th (D.S.); chutima.son@nstda.or.th (C.S.); sithichoke.tan@nstda.or.th (S.T.); somsak.lik@biotec.or.th (S.L.); supawadee@biotec.or.th (S.I.); chettida.sri@biotec.or.th (C.S.); kewarin.kla@biotec.or.th (K.K.); malineec@biotec.or.th (M.S.); thipmanee.hle@ncr.nstda.or.th (T.H.)

2 Thailand Institute of Scientific and Technological Research, Pathum Thani 12120, Thailand; sareeya@tistr.or.th

3 School of Bioresources and Technology, King Mongkut's University of Technology Thonburi, Bangkok 10140, Thailand; morakot@nstda.or.th

* Correspondence: alongkorn@biotec.or.th

Citation: Wasuwan, R.; Phosrithong, N.; Promdonkoy, B.; Sangsrakru, D.; Sonthirod, C.; Tangphatsornruang, S.; Likhitrattanapisal, S.; Ingsriswang, S.; Srisuksam, C.; Klamchao, K.; et al. The Fungus Metarhizium sp. BCC 4849 Is an Effective and Safe

Mycoinsecticide for the Management of Spider Mites and Other Insect Pests. Insects 2022, 13, 42. https:// doi.org/10.3390/insects13010042

Academic Editor: Eric W. Riddick

Received: 12 November 2021

Accepted: 25 December 2021

Published: 30 December 2021

Publisher's Note: MDPI stays neutral with regard to jurisdictional claims in published maps and institutional affiliations.

Copyright: (C) 2021 by the authors. Licensee MDPI, Basel, Switzerland. This article is an open access article distributed under the terms and conditions of the Creative Commons Attribution (CC BY) license (https:// creativecommons.org/licenses/by/ $4.0 /)$.
Simple Summary: The spider mite is a destructive pest of various crops during warm and dry conditions in tropical countries, including Thailand. The pest is difficult to control despite synthetic acaricide use. In the field, insect populations gradually develop resistance to synthetic pesticides over long-term use. The use of entomopathogenic fungi is more human- and environmentally friendly. We searched and identified a potential fungal isolate from a culture collection, focusing on the genus Metarhizium. Metarhizium sp. BCC 4849 not only controls the spider mite but also plays a significant role as a natural regulator of other insect pests. Here, we investigated its infection process on the mite, optimized a conidial formulation for extended shelf life, and conducted toxicological assays in animals to assess its biosafety in humans. The fungal genome has been sequenced. The genomic data indicated that oxidoreduction proteins; zinc-, heme-, and iron-binding proteins; and transmembrane transporters are abundant in the genome.

Abstract: Five isolates of Metarhizium sp. were evaluated for their pathogenicity against the spider
mite (Tetranychus truncatus Ehara) (Acari: Tetranychidae) and Metarhizium sp. BCC 4849 resulted in
the highest mortality ( $82 \%$ ) on the 5th day post-inoculation (DPI). Subsequent insect bioassay data
indicated similar high virulence against five other insects: African red mites (Eutetranychus africanus
Tucker) (Acari: Tetranychidae), bean aphid (Aphis craccivora Koch) (Hemiptera: Aphididae), cassava
mealybug (Phenacoccus manihoti Matile-Ferrero) (Hemiptera: Pseudococcidae), sweet potato weevil
(Cylas formicarius Fabricius) (Coleoptera: Brentidae), and oriental fruit fly (Bactrocera dorsalis Hendel)
(Diptera: Tephritidae), at mortalities of $92-99 \%$, on 3rd-6th DPI, and in laboratory conditions. The
pathogenicity assay against E. africanus in hemp plants under greenhouse conditions indicated
85-100\% insect mortality on 10 th DPI using the fungus alone or in combination with synthetic
acaricide. Genome sequencing of Metarhizium sp. BCC 4849 revealed the high abundance of proteins
associated with zinc-, heme-, and iron-binding; oxidation-reduction; and transmembrane transport,
implicating its versatile mode of interaction with the environment and adaptation to various ion
homeostasis. The light and scanning electron microscopy indicated that at 24 host inoculation
(PI), adhesion and appressorial formation occurred, notably near the setae. Most infected mites had
stopped moving and started dying by $48-72 \mathrm{~h}$ PI. Elongated hyphal bodies and oval blastospores
were detected in the legs. At $96-120 \mathrm{~h}$ PI or longer, dense mycelia and conidial mass had colonized
the interior and exterior of dead mites, primarily at the bottom than the upper part. The shelf-life
study also indicated that conidial formulation combined with an oxygen-moisture absorber markedly 
enhanced the viability and germination after storage at $35^{\circ} \mathrm{C}$ for four months. The fungus was tested as safe for humans and animals, according to our toxicological assays.

Keywords: acaricide; hemp; hyphal body; insect pest; Metarhizium; shelf life; toxicology

\section{Introduction}

Species in the genus Metarhizium are well-known biopesticides for controlling a wide range of insect pests [1]. These pests included phytophagous mites, citrus rust mite, twospotted spider mite, and bulb mite [2]. The spider mite is an important pest of many crop plants in the greenhouse and the field such as cassava (Manihot esculenta Crantz) (Euphorbiales: Euphorbiaceae), durian (Durio zibethinus Murray) (Malvales: Bombacaceae), pepper (Piper nigrum L.) (Piperales: Piperaceae), tomato (Solanum lycopersicum L.) (Solanales: Solanaceae), potato (Solanum tuberosum L.) (Solanales: Solanaceae), bean (Phaseolus vulgaris L.) (Fabales: Fabaceae), corn (Zea mays L.) (Cyperales: Poaceae), strawberry, Fragaria ananassa (Weston) Dunchesne (Rosales: Rosaceae), and cannabis (Canabis indica L. and C. sativa L.) (Rosales: Cannabaceae) [3]. Marijuana and hemp had an estimated value of USD 35.8 billion each year and a market value of USD 688 million in 2016, respectively, in the USA [4]. Cassava is also an important economic crop in several tropical countries. Tetranychid mites resulted in devastating losses (14-47\% in the field) in cassava in the Philippines, Indonesia, and India [5,6]. Widely-used entomopathogenic fungi belong to species Hirsutella thompsonii Fisher (Hypocreales: Ophiocordycipitaceae), Paecilomyces (Isaria) fumosorosea Wize (Hypocreales: Cordycipitaceae) [7] Verticillium (Lecanicillium) lecanii Zimm (Hypocreales: Cordycipitaceae) [8], Beauveria bassiana (Bals.-Criv) Vuill (Hypocreales: Cordycipitaceae), and Metarhizium robertsii (Metschn) Sorokin (Hypocreales: Clavicipitaceae) $[9,10]$. M. robertsii was one of the first organisms used for management of agricultural pests. The pioneering immunologist Elie Metchnickoff initiated trials of this fungus against the wheat cockchafer Anisoplia austriaca Herbst (Coleoptera: Scarabaeidae) in 1879 [11]. One of the most successful biological control using Metarhizium was an application of two million hectares of sugar cane plantations in Brazil with $M$. robertsii to control spittlebugs (Clastoptera achatina Germar) (Hemiptera: Clastopteridae) [12].

Infection of Metarhizium sp. on insect hosts consists of several stages [13]. The fungal conidia adhere to the waxy cuticle of the host and germinate [14]. The germ tubes can differentiate into the appressorium, from which penetration occurs through the penetration peg. The fungus can degrade and penetrate the insect cuticle using a combination of cuticledegrading enzymes and mechanical pressure while overcoming any stresses encountered along the way $[15,16]$. The fungus then colonizes the insect hemolymph, causing the mycosis of insects. When the host dies, the hyphae extrude the cadaver to the outer environment and form a dense mycelial network and green spores [17]. This event starts a new round of infection [18].

In the field, insect populations gradually develop resistance to synthetic pesticides. Farmers then increase the dose and finally discover that the pesticides are no longer effective. The field population of whitefly (Bemisia tabaci Gennadius) (Hemiptera: Aleyrodidae) developed resistance against pyrethroids, organophosphates, and neonicotinoids after their prolonged use for over 30 years [19]. Resistance against avermectin and pyridaben was detected in the population of the spider mite Tetranychus truncates Ehara (Acari: Tetranychidae) and could be inherited by their progeny [20]. An alternative strategy of chemical control needs to be developed. A more human- and environmentally friendly approach is necessary and will reduce the impacts of chemical accumulation in the environment and health risks associated with pesticide use. Entomopathogenic fungi can play a significant role as natural regulators of the insect and mite populations. They can be applied alone or as a combination with synthetic pesticides/acaricides. The combined use of entomopathogenic fungi with a lower dose of chemical insecticides led to a synergistic additive 
effect and increased mortality of several insect pests. The lower dosage of the chemicals not only enhanced the efficacy of the entomopathogen but also led to relatively short exposure times on the insects [21,22]. In this study, we screened five Metarhizium sp. isolates against the cassava mite, Tetranychus truncatus Ehara (Acari: Tetranychidae). Metarhizium sp. BCC 4849 had the highest pathogenicity against this mite and five other insect pests. This study documented the infection mechanism under laboratory conditions. In addition, the effect of the fungus alone and in combination with acaricide fenpyroximate against African red mite, in hemp plants (Canabis sativa L.) (Rosales: Canabaceae) under greenhouse conditions, was evaluated. Shelf life of conidial powder formulations at different temperatures was performed. Lastly, biosafety assessments in animals for the human safety evaluation, including acute oral toxicity, acute dermal toxicity, acute dermal irritation, acute eye irritation, and acute pulmonary toxicity/pathogenicity, were tested.

\section{Materials and Methods}

\subsection{Fungal Strains}

All the fungal isolates used in this study were obtained from Thailand Bioresource Research Center (TBRC). These included Metarhizium sp. BCC 30,455, BCC 4849, TBRC 4908, TBRC 4912, and M. anisopliae BCC 16,000. Each strain was grown on potato dextrose agar (PDA; Difco, Detroit, MI, USA) in the dark at $25^{\circ} \mathrm{C}$ for 12 days. Conidia were scraped from culture media and transferred into $10 \mathrm{~mL}$ of sterile water, then suspended in $0.2 \%$ tween-80 (Loba Chemie, Mumbai, India). The conidial density was adjusted to $1 \times 10^{8}$ conidia $\cdot \mathrm{mL}^{-1}$ for use as inoculum in insect bioassays.

\subsection{Insect-Rearing Culture}

Cassava mite (T. truncates) was obtained from the Department of Agricultural Extension, Thailand. The adults were maintained on potted bean plants in a greenhouse and reproduced on surface-sterilized mulberry leaves under laboratory conditions at 25-28 ${ }^{\circ} \mathrm{C}, 50-70 \%$ relative humidity (RH). Bean aphids (Aphis craccivora Koch) (Hemiptera: Aphididae), cassava mealybugs (Phenacoccus manihoti Matile-Ferrero) (Hemiptera: Pseudococcidae), and sweet potato weevil (Cylas formicarius Fabricius) (Coleoptera: Brentidae) were collected from vegetable, cassava, and sweet potato plantations, respectively, for subsequent bioassays. Oriental fruit flies (Bactrocera dorsalis Hendel) (Diptera: Tephritidae) were provided by the Thailand Institute of Nuclear Technology and reared on a sucrose-yeast extract-containing substrate.

\subsection{Microscopy of the Infection Process}

For light microscopy, cassava mites $(n=20-30)$ were inoculated by topical application with $0.2 \%$ coconut oil (Bioagricert, Samut Sakhon, Thailand)-mixed conidial suspension of Metarhizium sp. BCC 4849 at $1 \times 10^{8}$ conidia $\cdot \mathrm{mL}^{-1}$ and placed on mulberry leaves. The treatments were transferred to Petri-dishes and kept in a plastic box at $25{ }^{\circ} \mathrm{C}, 70-80 \% \mathrm{RH}$ in darkness. Light microscopy was used to observe the infection process of the Metarhizium strain on the insect at 24, 48, 72, 96, and $120 \mathrm{~h}$ post-inoculation (PI). Five inoculated mites were observed for distribution and cell types and shape at each time point. The specimens were stained with $2.5 \mu \mathrm{L}$ lactophenol cotton blue (Sigma-Aldrich, St. Louis, MO, USA)

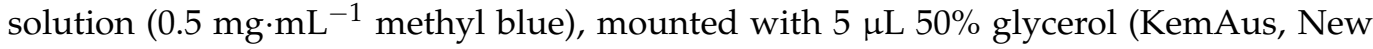
South Wales, Australia) on a glass slide, and observed under Nikon ECLIPSE Ti2-E (Nikon, New York, NY, USA).

We also performed scanning electron microscopy (SEM) of the inoculated cassava mites as follows. Adult mites were inoculated as described above and fixed with 5\% glutaraldehyde (Sigma-Aldrich, St. Louis, MO, USA). The insects were washed three times with phosphate buffer saline (PBS) (Sigma-Aldrich, St. Louis, MO, USA) (pH 6.98) and post-fixed in 2\% osmium tetroxide (Electron Microscopy Sciences, Hatfield, PA, USA) in the same buffer for $16 \mathrm{~h}$. Specimens were dehydrated in a gradient series from 30 to 100\% ethanol and dried under $\mathrm{CO}_{2}$ (critical point dryer model CPD K850; Quorum, East Sussex, 
United Kingdom). Specimens were mounted on a metal stub, sputter-coated with a layer of gold in a coater model Q150RS (Quorum), and documented under FE-SEM model SU5000 (Hitachi, Tokyo, Japan).

\subsection{Insect Bioassays}

Five isolates in the genus Metarhizium were separately applied on adult cassava mites in a single dose of $1 \mathrm{~mL}$ of conidial suspension at $1 \times 10^{8} \mathrm{conidia} \cdot \mathrm{ml}^{-1}$ and maintained on mulberry leaves. For all treatments, including an untreated control, mulberry leaves were placed on sterile tissue papers and moisturized with $2 \mathrm{~mL}$ of sterile water in $150 \mathrm{~mm}$ Petri dishes. Each treatment had 5 replicates ( $n=30$ for each replicate). The bioassay was repeated twice. Only the Metarhizium isolate with the highest virulence against cassava mites was selected for subsequent insect bioassays.

We performed insect bioassays of Metarhizium sp. BCC 4849 (that had the insect virulence) against four other pests, including bean aphid, cassava mealybug, oriental fruit fly, and sweet potato weevil, under laboratory conditions. Bioassays against the third nymphal stages of bean aphid and cassava mealybug (five replicates; $n=20$ each) were conducted as described above with some modifications. Bean and cassava leaves were used for feeding bean aphids and mealybugs, respectively, during the assays. For the bioassay against sweet potato weevil, the larval stage of potato weevil was inoculated by a 30-s dip in $1 \mathrm{~mL}$ of conidial suspension at $1 \times 10^{8}$ conidia $\cdot \mathrm{mL}^{-1}$ and then fed with sweet potato pieces. There were three replicates $(n=10$ each). Control insects were treated with the same solution without fungal conidia. Mortality data were recorded daily for five days. We also performed a bioassay against adult oriental fruit flies (three replicates; $n=20$ each). Adult flies were sedated at $-20^{\circ} \mathrm{C}$ for $15 \mathrm{~min}$ before fungal inoculation. For each replicate, 20 fruit flies were gently mixed with $1 \mathrm{~g}$ of Metarhizium sp. BCC 4849-colonized rice grains in a $50-\mathrm{mL}$ tube for $1 \mathrm{~min}$. Control flies were treated similarly with the rice grains without fungal conidia. Treated flies were transferred to plastic cages that had a feeding substrate containing $3.5 \mathrm{~g} / \mathrm{L}$ yeast extract and $1 \mathrm{~g} / \mathrm{L}$ sucrose and water and maintained at $25-30{ }^{\circ} \mathrm{C}$, $70-80 \%$ relative humidity $(\mathrm{RH})$, and photoperiod of 10:14 h (L:D). Insect mortality was recorded daily. Fly cadavers were placed in a moistened paper to observe mycosis. For the four pests tested, the pathogenicity assays were repeated twice.

\subsection{Greenhouse Trials and Application Treatment}

We conducted greenhouse trials of Metarhizium sp. BCC 4849 against African mite, an important pest of hemp. Fifty potted hemp plants, hybrid varieties RPF1, RPF2, RPF3, and RPF4, were naturally infested with African mites. Two trials were conducted at a greenhouse, Thailand Science Park, from 7 to 17 October 2020 and from 11th to 21st February 2021. Mean temperature, $\mathrm{RH}$, and photoperiod in the greenhouse were $29 \pm 1{ }^{\circ} \mathrm{C}, 75 \%$, and 10:14 h (L: D), respectively. Preventing an outbreak of red mites in the greenhouse was a high priority. Consequently, an untreated control was not included in this study. Therefore, we tested two fungal treatments in the greenhouse trials. The fungus Metarhizium sp. BCC 4849 was applied alone or in combination with $0.002 \%(w / v)$ acaricide fenpyroximate. The conidial suspension was prepared in 0.025\% APSA-80 (Amway, Ada, MI, USA). The fungal treatment was applied three times at a 3-d interval. The E. africanus population was determined one day before application and after the 1st, 2nd, and 3rd application. For the insect determination in each treatment, five leaves were randomly picked at the middle and bottom sections of the hemp plant three days after each application and microscopically checked for the number of live and dead nymphs and adults per leaf under a stereo microscope EZ4 HD (Leica, Wetzlar, Germany). All leaves were placed on moist paper in a $150 \times 15 \mathrm{~mm}$ Petri dish to observe mycosis.

\subsection{Determination of Conidiation in Different Substrates}

The conidial suspension was prepared by dislodging from 12-d-old culture and adjusted to a final concentration of $1 \times 10^{7}$ conidia. $\mathrm{mL}^{-1}$. This was used as an inoculum 
for the determination of conidiation in different culture media. These media included PDA, half-strength PDA, malt extract agar (MEA), oatmeal agar (OMA), and Sabouraud dextrose agar supplemented with $1 \%$ yeast extract (SDAY). All the cultures were conducted in $90 \times 15 \mathrm{~mm}$ Petri dishes by transferring and spreading $100 \mu \mathrm{L}$ of the conidial suspension and incubating at 25,28 , and $30{ }^{\circ} \mathrm{C}$. After incubation for 7 and 10 days, conidia were harvested by dislodging as described above, in $10 \mathrm{~mL}$ of $0.2 \%$ tween-80 (Loba Chemie, Mumbai, India) in sterile water. Conidial densities were determined using a hemocytometer. There were two replicates for each treatment, and the experiment was repeated twice.

\subsection{Conidial Powder Formulation and Shelf-Life Assay}

Metarhizium sp. BCC 4849 conidia were grown in rice, the substrate for large-scale production. Aliquots of $200 \mathrm{~g}$ of rice grains in polyethylene bags were sterilized in an autoclave for $20 \mathrm{~min}$ at $121^{\circ} \mathrm{C}$. The substrate was inoculated with $1 \mathrm{~mL}$ of conidial suspension at $1 \times 10^{8}$ conidia $\cdot \mathrm{mL}^{-1}$ and incubated at $25-28^{\circ} \mathrm{C}$ for 14 days. Conidia were then harvested from $200 \mathrm{~g}$ of the rice grains by resuspending in $300 \mathrm{~mL}$ of $0.2 \%$ tween- 80 and precipitation by centrifugation at $3857 \mathrm{~g}$ for $10 \mathrm{~min}$. After removal of the supernatant, the conidial pellet was resuspended in $30 \mathrm{~mL}$ of $0.2 \%$ tween-80, mixed with $100 \mathrm{~g}$ of sterile kaolin (Chemipan, Bangkok, Thailand), and air-dried in a biosafety cabinet class II NU440-400E (Nuaire, Plymouth, MN, USA) for 3 days to reduce the moisture content to $\sim 5 \%$, optimal for long-term storage. Aliquots of $50 \mathrm{~g}$ of conidia powder formulation were transferred to aluminized pouches. A dual-purpose oxygen/moisture-absorbing sachet (RP-3AN, Mitsubishi Gas Chemical Co., Tokyo, Japan) was enclosed in each pouch and sealed by heat. The conidia were incubated at different temperatures -25 and $35^{\circ} \mathrm{C}$. The control included the fungal conidia prepared as above and kept without the oxygen/moisture-absorbing sachet. There were three replicates for each treatment. The experiment was repeated twice. The conidial survival was performed by the determination of colony-forming units at 2, 4, 8, 10, 12, 14, and 16 weeks.

\subsection{Toxicological Testing in Animal Models}

Acute oral toxicity, acute dermal toxicity, acute dermal irritation/corrosion, and acute eye irritation/corrosion were performed according to Guidelines No. 423, 402, 404, and 405, respectively. All animal models were maintained and tested by Naresuan University Center for Animal Research. In addition, acute pulmonary toxicity/pathogenicity study was performed according to the Microbial Pesticide Test Guidelines of the U.S. EPA (OCSPP) 885.3150. Tier I. (1996) by Jai Research Foundation, India. For acute oral toxicity test, all rats were orally administered with the conidial powder of Metarhizium sp. BCC 4849, as described above, at the doses of 300 and $2000 \mathrm{mg} / \mathrm{kg}$ body weight. They were then observed for toxicity signs and symptoms for 14 days after administration. For acute dermal toxicity, Metarhizium sp. BCC 4849 at doses of 200, 1000, and $2000 \mathrm{mg} / \mathrm{kg}$ body weight was applied dermally to the shaved area of the dorsal skin of rats. They were observed for toxicity signs and symptoms for 14 days after patch application. For acute dermal and acute eye irritation/corrosion, Metarhizium sp. BCC 4849 was tested on the New Zealand white rabbits to observe the irritation of skin and eye. They were observed for toxicity signs and symptoms, including erythema and edema at 14 and 21 days after patch application into the skin and instillation into the eye. For acute pulmonary toxicity/pathogenicity study of Metarhizium sp. BCC 4849, the rats were given a single pulmonary (nasal instillation) dose of fungal conidia in PBS at $1.5 \times 10^{8} \mathrm{CFU} /$ rat. Rats were observed for 21 days with interim sacrifices scheduled on days $0,3,7$, and 14 , and at the terminal sacrifice on day 21 .

\subsection{De Novo Genome Assembly of Metarhizium sp. BCC 4849 and Gene Annotation}

The genomic DNA of Metarhizium sp. BCC 4849 was extracted and used to prepare a SMRTbell library with an insert size of approximately 10,000 bp according to the manufacturer's instruction (Pacific Biosciences, Menlo Park, CA, USA). DNA sequencing was performed with P6-C4 polymerase and chemistry using 360-min movie times on a PacBio 
RSII system (Pacific Biosciences). A total of 244,060 raw reads from 4 SMRT cells were corrected, and de novo assembled using the HGAP.3 protocol with default settings from the SMRTanalysis (v2.3) software package (Pacific Bioscience, Menlo Park, California, CA, USA). To obtain the genome draft with the highest quality, genome polishing was performed using Arrow and Quiver from the SMRTanalysis (v2.3.0). The completeness of the final genome assemblies was assessed using Benchmarking Universal Single-Copy Orthologs (BUSCO) (Swiss Institute of Bioinformatics, Lausanne, Switzerland) with the Fungi OrthoDB release 9. The Metarhizium sp. BCC 4849 genome annotations were created using the Augustus V3.2.1 program (Bioinformatics Group of the Institute for Mathematics and Computer Science of the University of Greifswald, Greifswald, Germany) using Metarhizium anisopliae as a gene model.

\subsection{Statistical Analyses}

All experiments in this study were repeated 2-5 times. There were three replicates in each experiment. Data were analyzed for statistical significance using ANOVA in SPSS package version 11.5 and Student's $t$-test (IBM, New York, NY, USA).

\section{Results}

\subsection{Virulence of Metarhizium sp. Strains against T. truncatus and Four Other Pests}

Among the five isolates tested, the isolate Metarhizium sp. BCC 4849 showed higher insect mortality (82\%) than the other isolates (Table 1). Furthermore, the isolate also had similarly high virulence against the nymphs of bean aphid and cassava mealybug; the larvae of sweet potato weevils; and the fruit fly adults at 96, 92, 92, and 99\% insect mortality, respectively, on 3th-6th DPI depending on the developmental stages and sizes of target pests (Table 2). The insects in untreated controls had no or very low mortalities during the experimental periods.

Table 1. Pathogenicity of Metarhizium isolates against the spider mite (Tetranychus truncatus) at the 5th day post inoculation (dpi).

\begin{tabular}{cc}
\hline Isolate & Insect Mortality (\%) \pm s.e.m. \\
\hline BCC 4849 & $82.4 \pm 0.1^{\mathrm{a}}$ \\
BCC 16,000 & $7.9 \pm 5.4^{\mathrm{c}}$ \\
BCC 30,455 & $32.8 \pm 18.1^{\mathrm{b}, \mathrm{c}}$ \\
TBRC 4912 & $37.3 \pm 16.4^{\mathrm{b}, \mathrm{c}}$ \\
TBRC 4908 & $44.9 \pm 20.4^{\mathrm{b}}$ \\
Control (non-treated) & $11.2 \pm 8.6^{\mathrm{b}, \mathrm{c}}$
\end{tabular}

The results were from two independent experiments. Data shown are mean \pm s.e.m. Different letters indicate statistical significance (Tukey's HSD, $p<0.05$ ).

Table 2. Virulence of Metarhizium sp. BCC 4849 against various insect pests, inoculation techniques, and effects on insect mortality on days post inoculation (DPI). Conidial suspension was applied at $1 \times 10^{8}$ conidia $\cdot \mathrm{mL}^{-1}$.

\begin{tabular}{cccc}
\hline Target Pest & Inoculation Technique & DPI & Insect Mortality (\%) \pm s.e.m. \\
\hline Cassava mite (Tetranychus truncatus) & Topical application & 5 & $82.4 \pm 0.1$ \\
Bean aphid (Aphis craccivora) & Topical application & 3 & $96.0 \pm 5.5$ \\
Cassava mealybug (Phenacoccus manihoti) & Topical application & 3 & $92.0 \pm 5.7$ \\
Sweet potato weevil (Cylas formicarius) & Dipping & 5 & $91.9 \pm 7.3$ \\
Oriental fruit fly (Bactrocera dorsalis) & Mixing with dry conidia & 6 & $98.9 \pm 1.9$ \\
\hline
\end{tabular}

\subsection{Metarhizium sp. BCC 4849 Infection of the Cassava Mites}

The lactophenol cotton stained the conidia and fungal cells located outside the insect body blue, which made it easier to differentiate the fungal cells formed inside the insect as unstained, transparent cells. After inoculation by $24 \mathrm{~h}$, all the cassava mites were still 
alive. Several conidia had germinated, and some produced appressoria on the cuticle (Figure 1A,B). Conidial germination and appressorial formation were also detected at the legs and antenna. Unstained hyphal bodies could be observed inside the leg hemocoel (Figure 1C). These in-vivo-produced fungal cells were formed and developed after the fungus gained entry into the host. These cells could have different lengths and appear irregular in shape. Within the femur, long hyphal cells were formed in the leg hemocoel (Figure 1C). By 48 h PI, most inoculated mites had stopped motile and feeding. Infected mites had started to die by $72 \mathrm{~h}$ PI. Long hyphae and hyphal bodies multiplied extensively in the leg hemocoel (Figure 1D). Hyphal fragmentation, as a means of asexual reproduction, was also documented (arrowheads in Figure 1E).

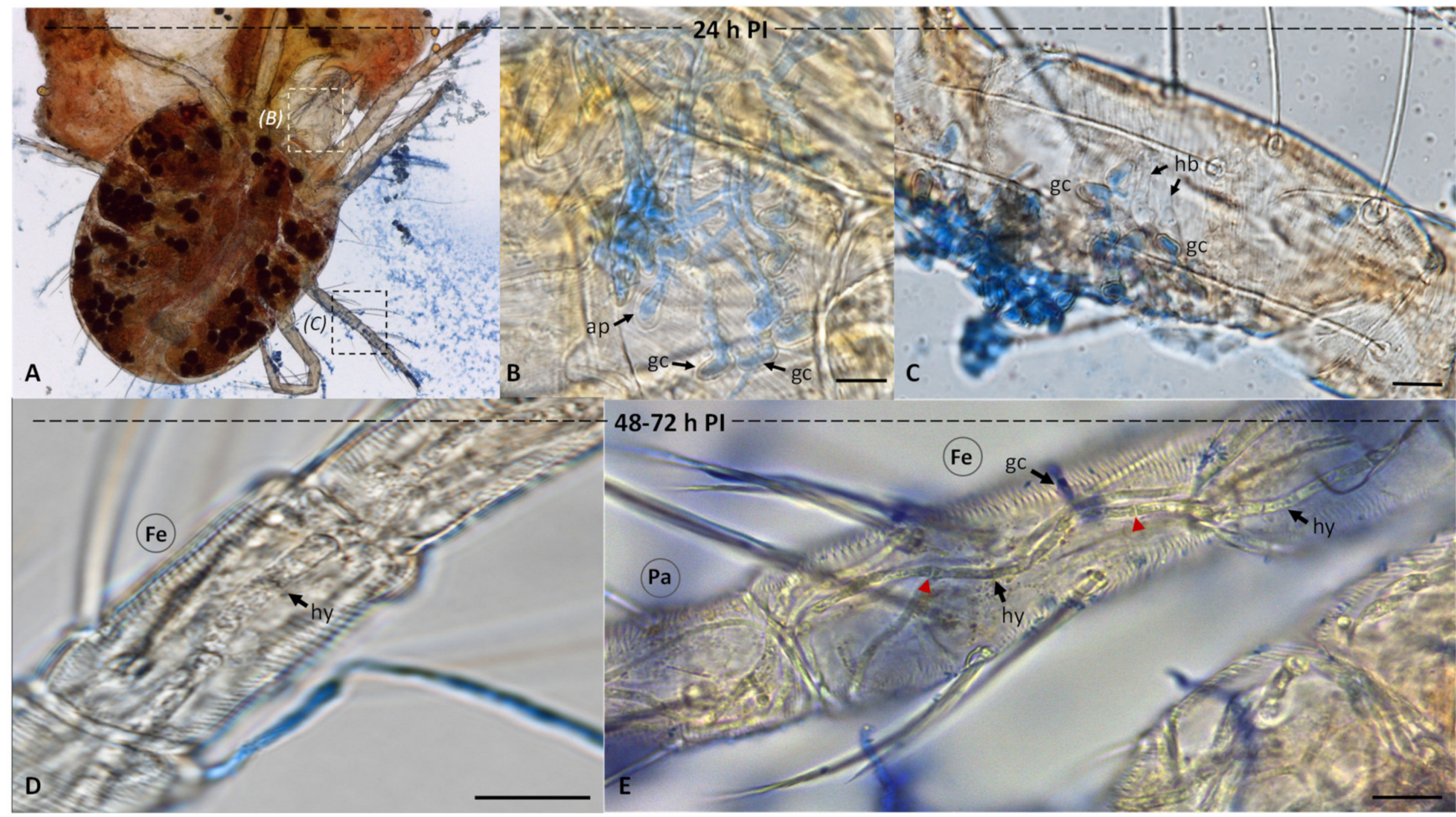

Figure 1. Light micrographs of cassava mites infected with Metarhizium sp. BCC 4849 stained with lactophenol blue 24-72 h post-inoculation (PI). (A) At 24 PI, a fungal-colonized mite was observed. (B,C) Germinating conidia (gc), appressoria (ap), and hyphal bodies (hb) were found at the side of the insect body and the leg, respectively. The infection sites were close to the bases of seta on a living mite, Bars, $10 \mu \mathrm{m}$. (D) At 48-72 h PI, we observed dead cassava mites filled with Metarhizium sp. BCC 4849 cells. The hyphae (hy) were found in the hemocoel at the femur (Fe). Bar, $10 \mu \mathrm{m}$. (E) A network of several hyphae colonized the femur and patella (Pa). Bar, $20 \mu \mathrm{m}$.

The light microscopy also indicated that by 72-96 h after inoculation, internal organs and tissues of infected mites had become heavily colonized by the fungus. An extensive hyphal network was observed inside the infected mites (Figure 2A). Several oval-shaped blastospores, cylindrical-shaped hyphal bodies, and hyphae were present in the anterodorsal (Figure 2B). The extrusion occurred after $120 \mathrm{~h}$ PI. Dense mycelia had colonized the interior of dead mites-mycelia emerging from cadavers and forming a mass of conidia (Figure 2C). At the exterior, the fungal conidia could be seen forming in a chain (Figure 2D). After the insect death, macroscopic observation indicated mycelial growth and conidiogenesis on the cadavers, shown by the white and greenish colorations on the body surface, respectively. 


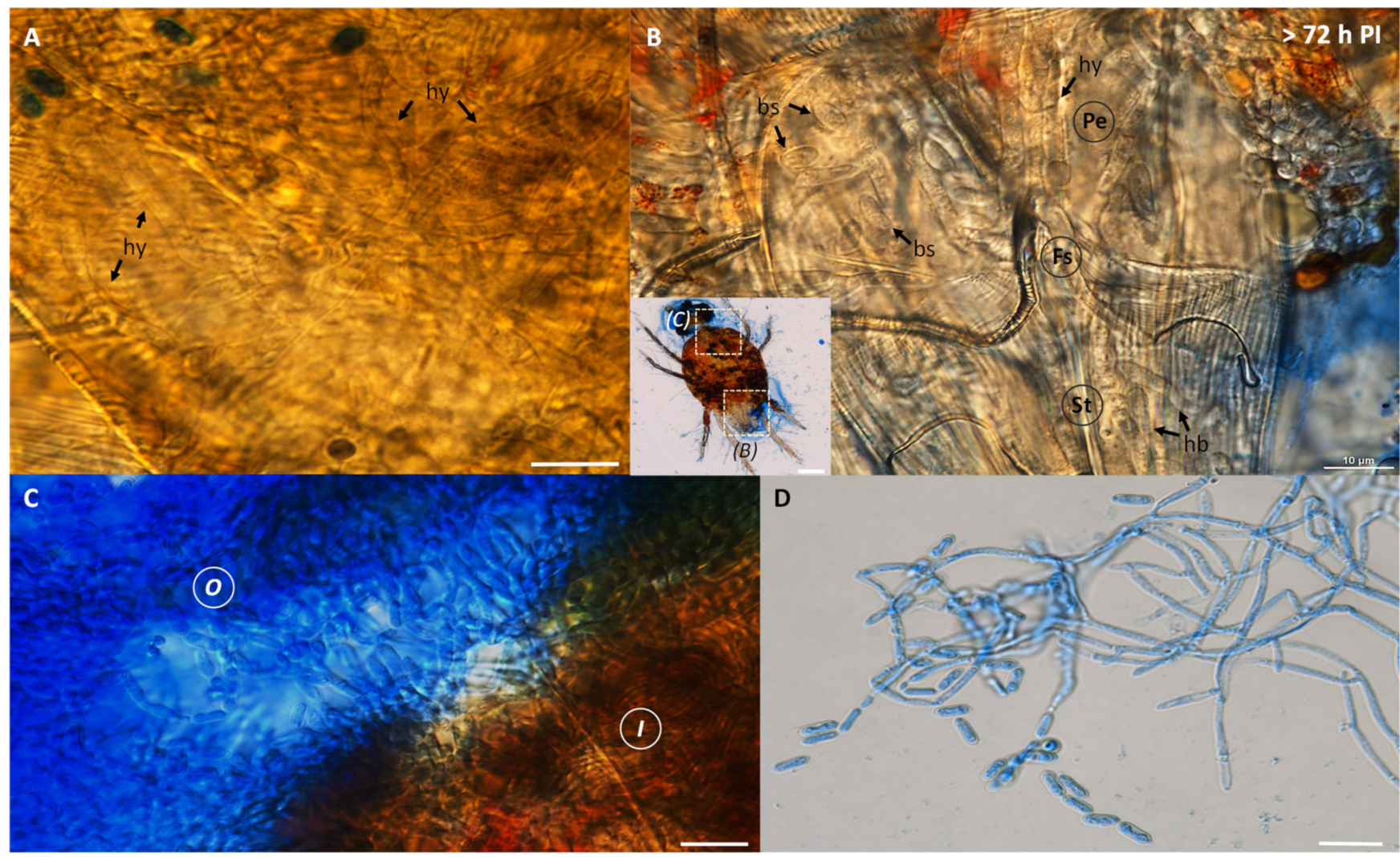

Figure 2. Light micrographs of dead cassava mites at a period longer than $72 \mathrm{~h}$ PI. (A) Several hyphae (hy) were observed inside the insect body. (B) A close-up view of anterodorsal section, including the feeding stylets (Fs), peritreme (Pe), and stylophore (St), showed numerous blastospores (bs) and hyphal bodies. (C,D) Dense mycelia and a mass of conidia appeared inside (I) and outside (O) of the hosts. Chains of cylindrical-shaped conidia Metarhizium sp. BCC 4849 were also found at the exterior of the dead host. Bars, $10 \mu \mathrm{m}$.

The SEM demonstrated that the conidial surface of Metarhizium sp. BCC 4829 had the rodlet bundles packed and arranged tightly throughout the surface (Figure 3A). These fascicle rodlet bundles are a structural feature composed of hydrophobin proteins, which are crucial for adhesion to the host. The microscopic analysis confirmed that the conidia adhered to nearly all the insect body parts. The oblong-to-cylindrical-shaped conidia were also suitable for attachment with the striae and integumentary lobes of the mite surface (Figure 2B). The conidia germinated and developed into the germ tube on the epicuticle (Figure 3B,C) and formed appressorium (Figure 3C) by $24 \mathrm{~h}$ PI. At $48 \mathrm{~h}$ PI, most conidia germinated, developed into hyphae, and penetrated at the socket between coxa (Figure 3D). The fungus overcame the host immunity and grew extensively inside the mites, as demonstrated above (Figures 1 and 2). After the host died, the fungus extruded the cadavers through openings, such as anal valves (Figure 3E), anal opening, or body cracks, at $72 \mathrm{~h}$ PI or longer. By $120 \mathrm{~h} \mathrm{PI}$, dense mycelia and conidia had colonized the interior and exterior of cadavers. We observed more clump of conidia at the bottom part of the body than the upper part (Figure 3F). 


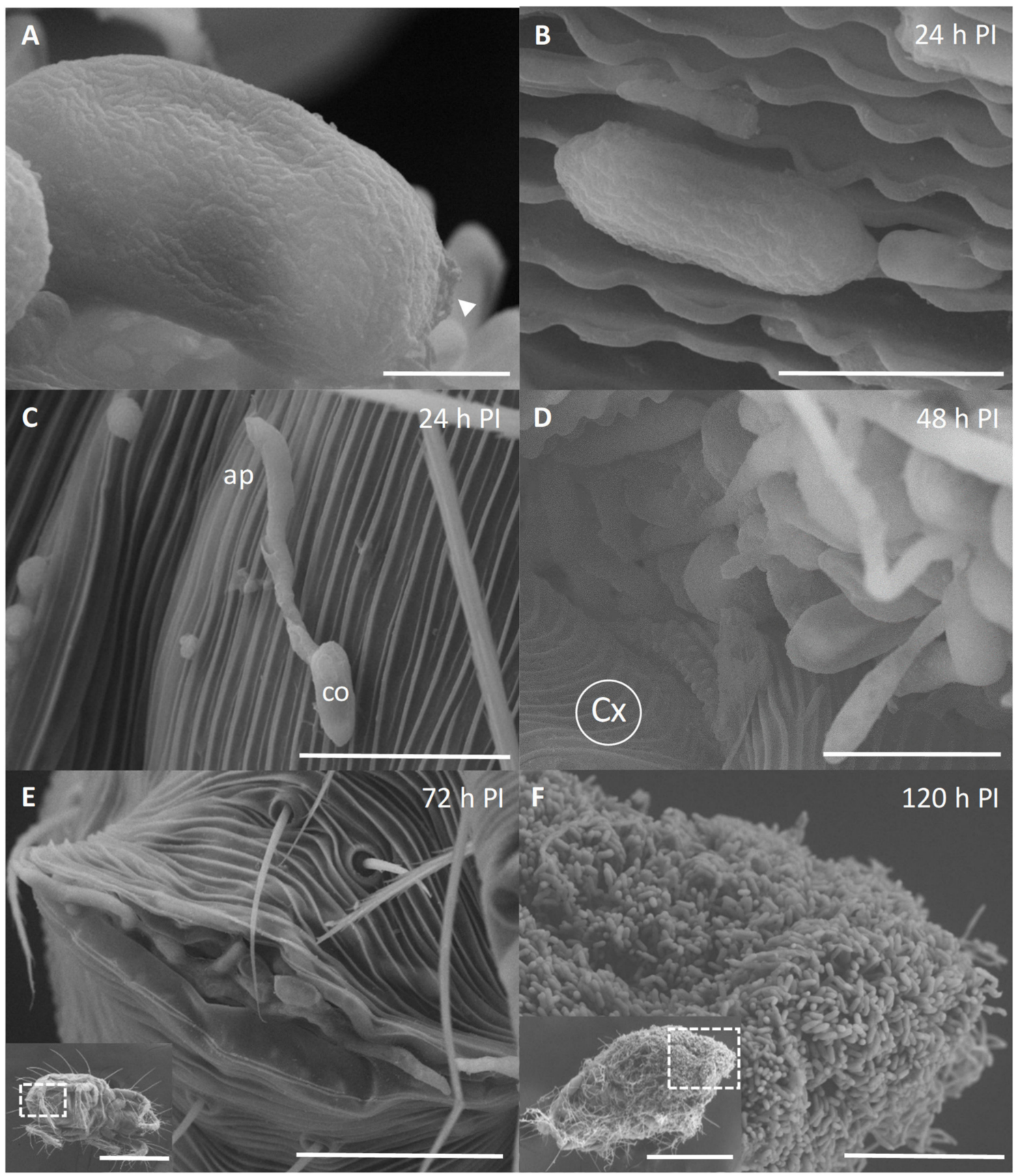

Figure 3. Scanning Electron micrographs of Metarhizium sp. BCC 4849 growing on a surface of cassava mites. (A) The arrangement of rodlet bundles on the surface of Metarhizium sp. BCC 4849 conidia. A conidial scar was seen after abstriction. Bar, $1 \mu \mathrm{m}$. (B) A germinating conidium was embedded in the striae integumentary lobes of the mite cuticle. Bar, $3 \mu \mathrm{m}$. (C) At $24 \mathrm{~h}$ PI, a germinating conidium (co) formed appressorium (ap) on the cuticle. Bar, $10 \mu \mathrm{m}$. (D) Conidia and hyphae extensively grew and developed for penetration at the socket of coxa (Cx) at $48 \mathrm{~h}$ PI. Bar, $5 \mu \mathrm{m}$. (E) At $72 \mathrm{~h} \mathrm{PI}$, fungal cells and hyphae extruded from the anal opening (indicated by the square in the inset; bar $200 \mu \mathrm{m}$ ). Bar, $20 \mu \mathrm{m}$. (F) Numerous conidia were present around the insect body, especially opisthosoma (indicated by the square in the inset; bar $200 \mu \mathrm{m})$. Bar, $10 \mu \mathrm{m}$.

\subsection{Efficacy of Metarhizium sp. and Diluted Acaricide Applications on E. africanus Mortality in Greenhouse}

The first greenhouse trial of topical application showed similarly high mortality of E. africanus in the two treatments. On the 7th day after application, the mortalities of red 
mites were 95-96\% in the fungus-only treatment and the fungus-fenpyroximate combined treatment (Figure $4 \mathrm{~A}$ ). At the end of the observation period on day $10 \mathrm{PI}$, the mite mortalities were $99-100 \%$, indicating that the fungus killed all the insects regardless of the chemical use at this time point.

A

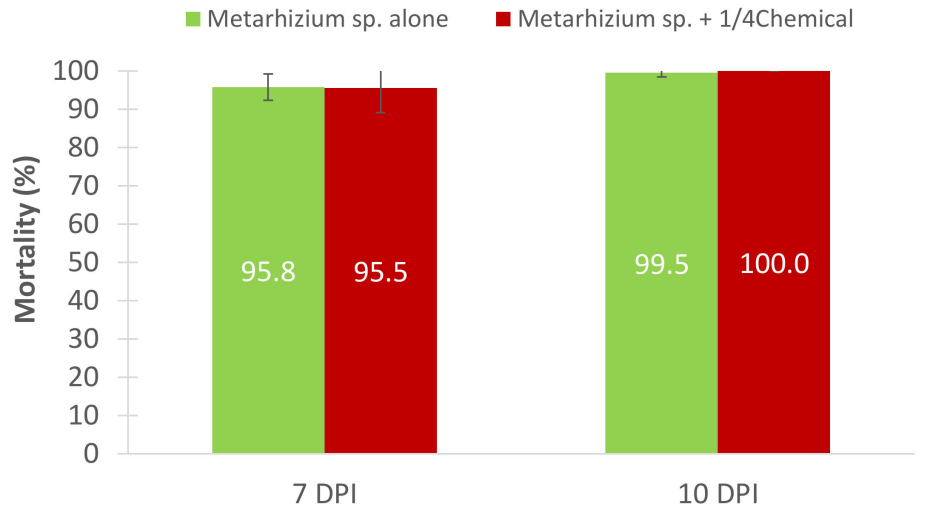

1st GH

B
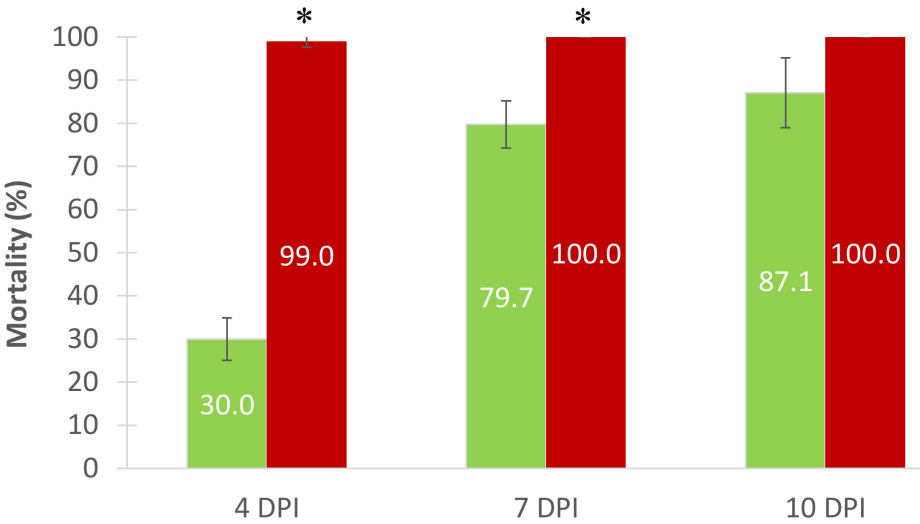

2nd GH
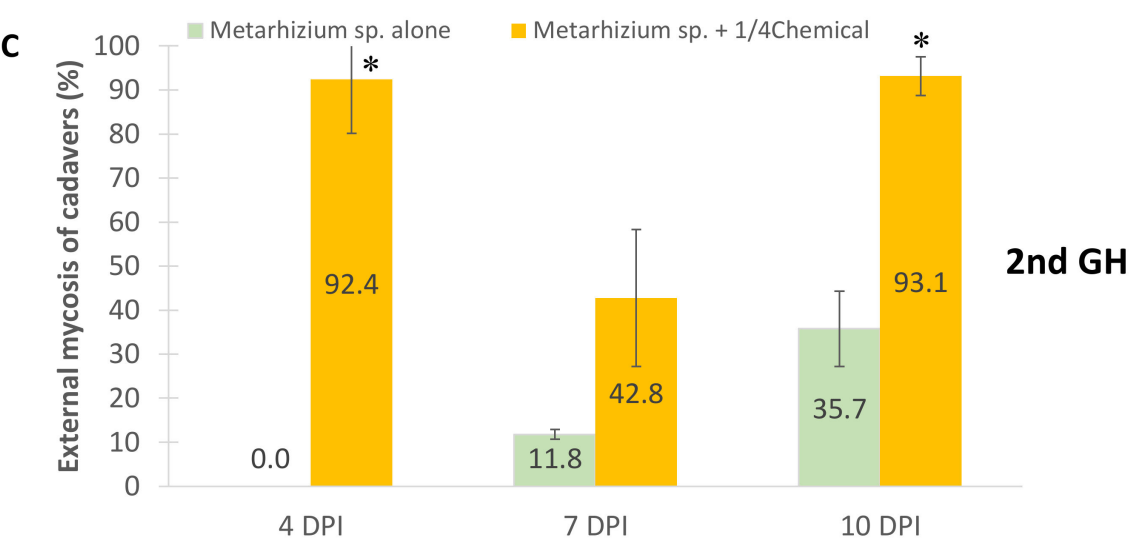

$10 \mathrm{DPI}$

Figure 4. Greenhouse trials of Metarhizium sp. BCC 4849 against the African mite E. africanus, an important pest of hemp plants. (A,B) The first and second trials of the treatment of the fungus alone and the fungus combined with a one-fourth dose of synthetic acaricide, respectively. (C) Mycosis percentage of the cadavers in the second trial. Data shown are mean \pm s.d. Asterisks indicate statistical significance between two treatments (Student's $t$-test: ${ }^{*}, p<0.05$ ).

In the second trial, high mortalities were also found in the mites treated by the fungus alone or the fungus and chemical combination on days 7 and 10 after application. However, the mortalities of Metarhizium-sp.-BCC-4849-inoculated mites slightly decreased to 80-87\%. Furthermore, application of the fungus alone caused a marked and significant $(p=0.03)$ decrease of mite mortality on day $4 \mathrm{PI}$, compared to the fungus-chemical combination (Figure 4B). These data suggested that fenpyroximate helped the fungus infect and kill 
the mites faster than the fungus alone during the early phase of host infection. We also determined the external mycosis of mite cadavers to verify the completion of the fungal infection cycle. The frequencies of mycosis found in the fungus-fenpyroximate treatment were higher than the treatment of the fungus alone throughout the experimental period (Figure 4C).

\subsection{Genome Sequencing and Assembly of Metarhizium sp. BCC 4849}

The whole-genome shotgun strategy was performed to sequence and assemble Metarhizium sp. BCC 4849 genome from PacBio long-read data. A total of 244,060 raw reads $(1.73 \mathrm{~Gb})$ represented $43.25 \times$ coverage based on the estimated genome size of $40 \mathrm{Mb}$. We selected 81,983 of the longest reads $(25 \times$ coverage) as seed reads for base correction and de novo assembly. After genome polishing, we obtained 26 contigs that covered $37.9 \mathrm{Mb}$ with $\mathrm{N}_{50}$ length of $3.51 \mathrm{Mb}$ (L50 = 5 scaffolds). To further evaluate the completeness of genome assembly, genome was checked with the program BUSCO using a fungi-specific database of 290 genes. The Metarhizium sp. BCC 4849 genome recovered $99.7 \%$ of the highly conserved orthologs in the fungi dataset, with $99.0 \%$ identified as "complete" and $0.7 \%$ identified as "partial". The draft whole-genome sequence of Metarhizium sp. BCC 4849 was deposited at GenBank under the accession number MWYT00000000. An ab initio prediction based on $\mathrm{M}$. anisopliae gene model was used for gene prediction. The genome annotations of Metarhizium sp. BCC 4849 indicated 10,559 protein-coding genes. The average gene size was 1503 bp with 2.8 exons per gene.

The functions of 10,559 predicted proteins were annotated using Interproscan version 5.46-81 [23]. The functionally annotated proteins were then categorized based on gene ontology (GO) molecular function, biological process, and cellular location [24] (Figure 5). Metarhizium sp. BCC 4849 had approximately 14.5\% encoded genes associated with zinc-, heme-, and iron-binding (Figure 5A). Majority (25\%) of the proteins were in the oxidationreduction pathway, which is composed of 120 cytochrome P450 enzymes, 101 short-chain dehydrogenases/reductuases, and 43 zinc-binding dehydrogenases. A relatively high proportion $(7 \%)$ of the predicted proteins were related to transmembrane transport (Figure 5B). A high proportion of transmembrane transport proteins were in concordance with the predicted cellular locations of proteins. Out of all predicted proteins, the cellular locations of 3580 proteins were annotated. The majority of locations (42.2\%) were the cell membrane (Figure 5C). Furthermore, the hidden Markov model scan using SignalP [25] and TMHMM [26] detected 20 proteins with the transmembrane signals. The high abundance of proteins associated with the ion binding and transmembrane transport might implicate a fungal adaptation of ion homeostasis in Metarhizium sp. BCC 4849.

By comparison to the annotated genome of M. anisopliae ARSEF 549 [27], the Metarhizium sp. BCC 4849 genome had a higher number of genes involved in siroheme biosynthesis, dynein complex, and actin filament depolymerization. In contrast, the genome had fewer genes involved in mercury breakdown processes, such as organomercury catabolism and alkylmercury lyase activity, compared to M. anisopliae ARSEF 549.

\subsection{Effect of Subculture Media and Temperature on Sporulation}

Types of culture media, incubation period, and temperature were determined to optimize conidiation in Metarhizium sp. BCC 4849. The fungus grew and conidiated well in nearly all subculture media to $1.7-4.3 \times 10^{9}$ conidia per petri dish except on SDYA after ten days of incubation at $25^{\circ} \mathrm{C}$. The fungal growth on SDYA was mainly the mycelia and few conidia. The oatmeal agar medium generated the highest conidiation, ranging from $3.9-4.3 \times 10^{9}$ conidia per petri dish on the 10th day of incubation, which was significantly different from the other culture media regardless of temperature $\left(25,28\right.$, or $30{ }^{\circ} \mathrm{C}$ (Figure 6$)$ ). 


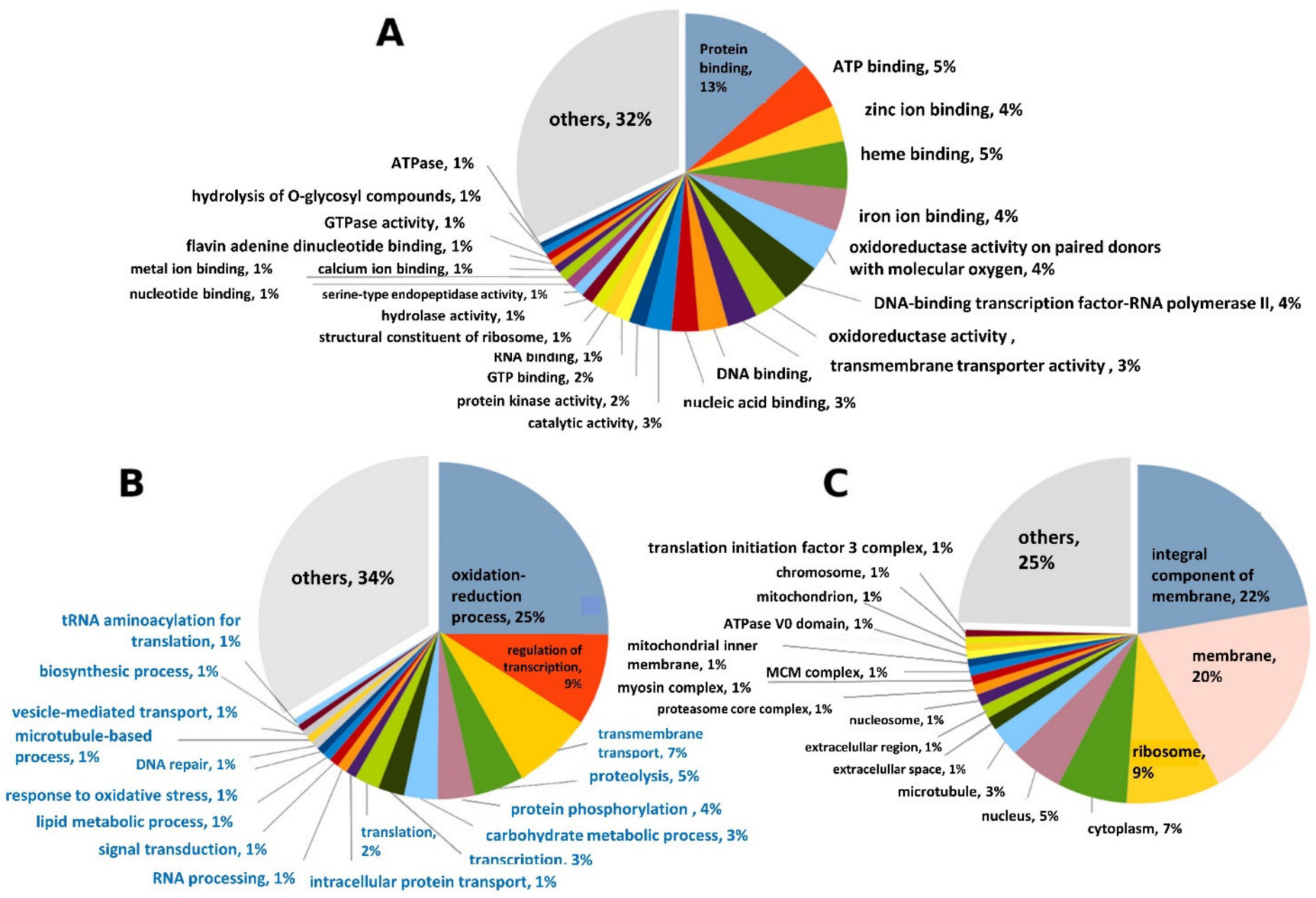

Figure 5. The functional category in the genome of Metarhizium sp. BCC 4849 predicted based on the gene ontology as follows: (A) molecular function, (B) biological process, and (C) cellular location.
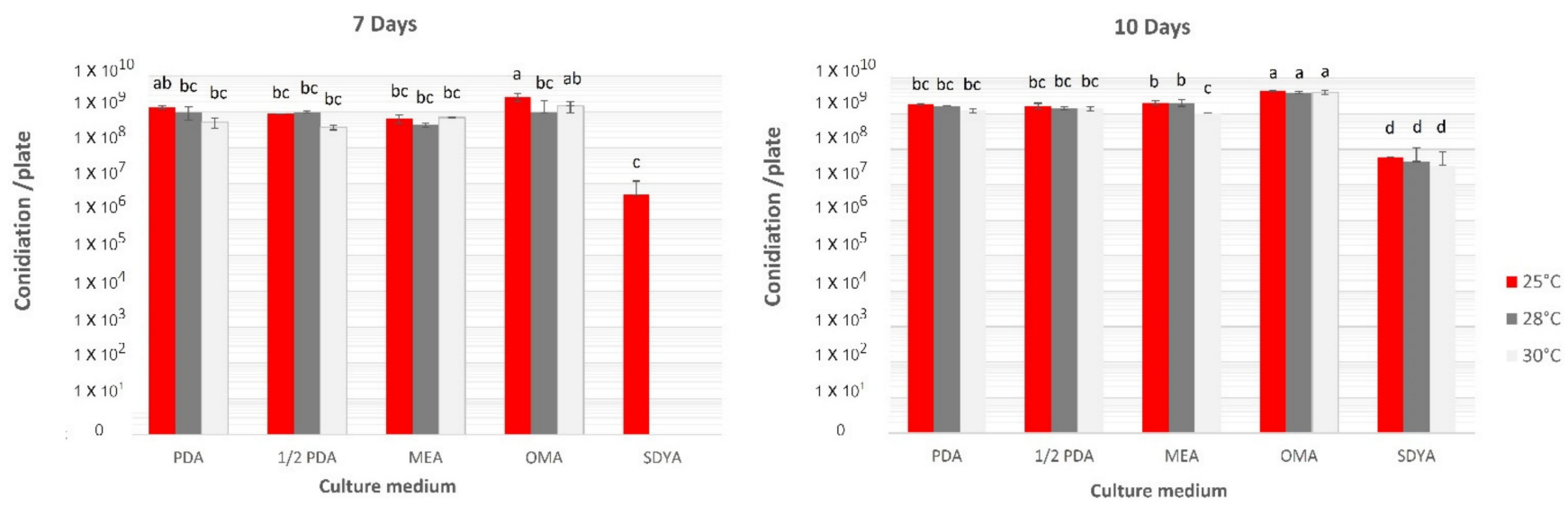

Figure 6. Conidiation of Metarhizium sp. BCC 4849 on difference culture media incubated at 25, 28 , and $30{ }^{\circ} \mathrm{C}$ at days 7 and 10 . Data shown are mean \pm s.e.m. Different letters indicate statistical significance among the treatments (Tukey's HSD, $p<0.05$ ).

\subsection{Effect of Moisture-Oxygen Absorber Sachets for Shelf-Life Extension}

The storage of Metarhizium sp. BCC 4849 with the moisture-oxygen absorber RP-3AN tremendously enhanced the shelf-life compared to that without RP-3AN. The fungal CFUs under the storage without RP-3AN were zero at the 4 th, 8 th, and 12 th weeks (Figure 7). In the first eight weeks of storage with RP-3AN, the fungal survival rates at $35^{\circ} \mathrm{C}$ were $42-48 \%$ of those at $25{ }^{\circ} \mathrm{C}$ (Figure 7 ). Later, the fungal survival rates at $35^{\circ} \mathrm{C}$ at the 12 th and 14 th week decreased to only $7-16 \%$ of those at the cooler temperature of $25^{\circ} \mathrm{C}$ (Figure 7). 
These data indicated that the fungus Metarhizium sp. BCC 4849 was considerably more viable at the cooler temperature of $25{ }^{\circ} \mathrm{C}$ than at $35^{\circ} \mathrm{C}$, the temperature commonly found during the daytime in the tropical region. After storage for 16 weeks at $35^{\circ} \mathrm{C}$, the fungal CFUs were slightly fewer at $1.8 \times 10^{8} \mathrm{CFU} \mathrm{g}^{-1}$, compared to $3.9 \times 10^{8} \mathrm{CFU} \mathrm{g}^{-1}$ at $25^{\circ} \mathrm{C}$. The active packaging treatment attributed to prolonged survival of conidia was compared to those without moisture-oxygen absorbers.

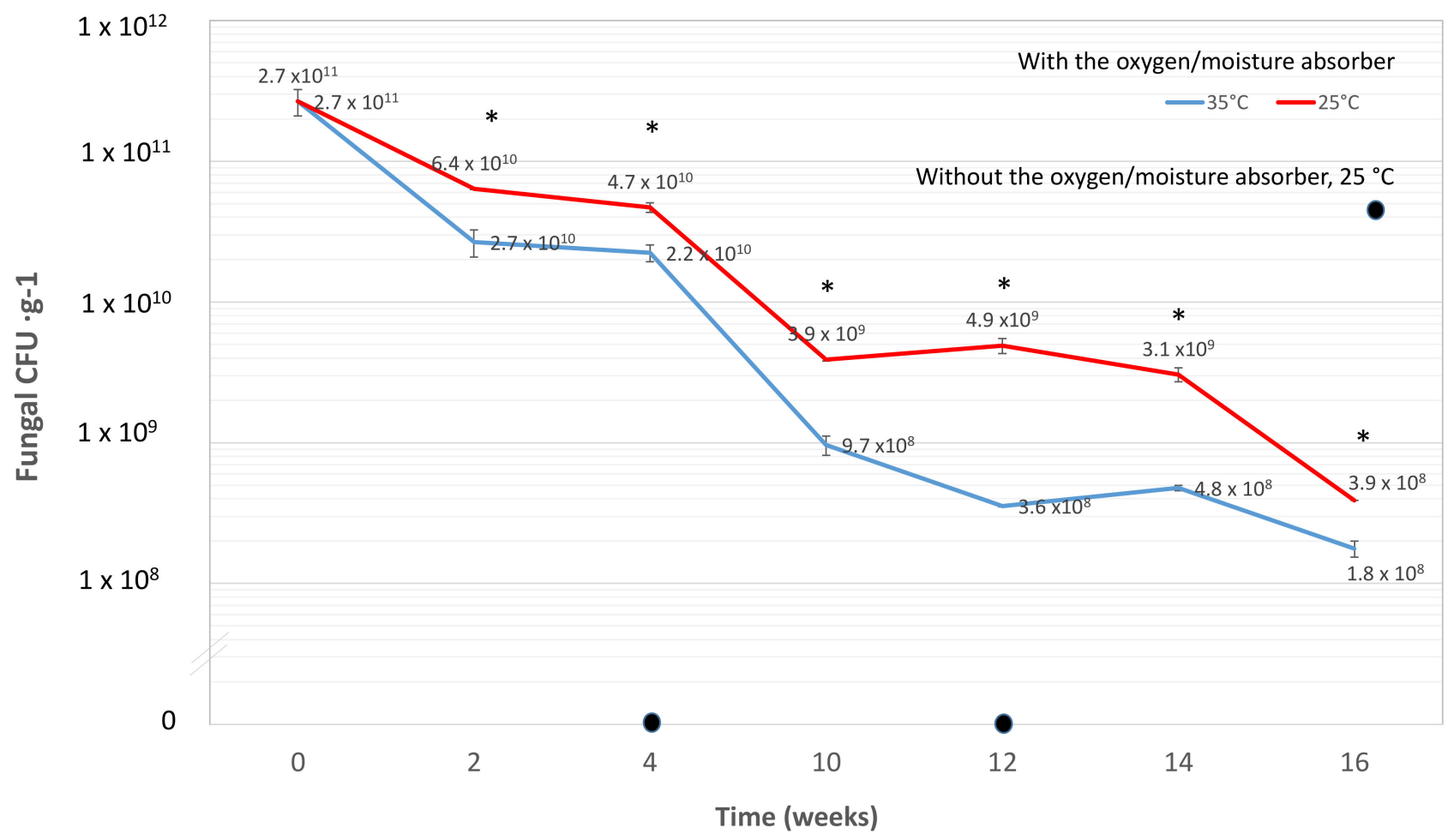

Figure 7. Shelf-life of Metarhizium sp. BCC 4849 conidia at two different temperatures of 25 and $35^{\circ} \mathrm{C}$ for 16 weeks. Two treatments include the conidia stored with and without the moisture $/ \mathrm{O}_{2}$ absorber sachet. Data shown are mean \pm s.e.m. Asterisks indicate statistical significance between the two treatments (Student's $t$-test: ${ }^{*} p<0.05$ ).

\subsection{Toxicological Testing in Animal Models}

For the acute oral toxicity test, the rats did not show abnormal signs of toxicity or mortality after oral administration of Metarhizium sp. BCC 4849 at the doses of 300 and $2000 \mathrm{mg} / \mathrm{kg}$ body weight. All rats were observed at $\frac{1}{2}, 1,2,3$, and $4 \mathrm{~h}$ after treatment and once daily for 14 days. Necropsy findings of all rats showed no gross pathological lesions. The oral LD 50 of Metarhizium sp. BCC 4849 in rats was $2000 \mathrm{mg} / \mathrm{kg}$ body weight (Table 3). For the acute dermal toxicity test, the rats did not show abnormal signs, symptoms, or mortality after patch application of Metarhizium sp. BCC 4849 at doses of 200, 1000, and $2000 \mathrm{mg} / \mathrm{kg}$ body weight. After a 14-day observation period, necropsy findings of all rats showed no gross pathological lesions. The dermal $\mathrm{LD}_{50}$ of the fungus in rats was $2000 \mathrm{mg} / \mathrm{kg}$ body weight. Acute dermal and acute eye irritation/corrosion were observed in New Zealand white rabbits. The results showed that Metarhizium sp. BCC 4849 did not cause any irritation of the skin and eye. Moreover, the result of acute pulmonary toxicity/pathogenicity study of Metarhizium sp. BCC 4849 showed no mortality and no infectivity and was not pathogenic in rats at a limit dose of $1.05 \times 10^{8} \mathrm{CFU} /$ rat. Therefore, the results indicated that Metarhizium sp. BCC 4849 did not cause any toxicity in animal models. 
Table 3. Biosafety assessment of Metarhizium sp. BCC 4849 conidia in animals.

\begin{tabular}{|c|c|c|c|c|}
\hline Study Type & Study Guideline & Animal & Dose Range/Level & GHS ${ }^{3}$ Toxic Classification \\
\hline Acute oral toxicity & OECD GLP $^{1} 423$ & Rats & $\mathrm{LD}_{50}>2000 \mathrm{mg} / \mathrm{kg}$ & Class 5 (Unclassified) \\
\hline Acute dermal toxicity & OECD GLP 402 & Rats & $\mathrm{LD}_{50}>2000 \mathrm{mg} / \mathrm{kg}$ & Class 5 (Unclassified) \\
\hline $\begin{array}{l}\text { Acute dermal } \\
\text { irritation/Corrosion }\end{array}$ & OECD GLP 404 & Rabbits & - & Class 5 (Unclassified) \\
\hline $\begin{array}{c}\text { Acute eye } \\
\text { irritation/Corrosion }\end{array}$ & OECD GLP 405 & Rabbits & - & Category 2B (mild irritant) \\
\hline $\begin{array}{l}\text { Acute pulmonary } \\
\text { toxicity/Pathogenecity }\end{array}$ & $\begin{array}{c}\text { U.S. EPA OCSPP }{ }^{2} \\
885.3150\end{array}$ & Rats & $\begin{array}{l}\text { No mortality } \\
\text { at } 1.05 \times 10^{8} \mathrm{CFU}\end{array}$ & \\
\hline
\end{tabular}

\section{Discussion}

This study demonstrated that the entomopathogen Metarhizium sp. BCC 4849 is a broad-range pathogen capable of infecting several important agricultural pests. These six targeted pests included the bean aphid, cassava mealybug, sweet potato weevil, oriental fruit fly, cassava mite, and African mite, across the orders Hemiptera, Coleoptera, and Diptera, and superorder Acariformes. Furthermore, our preliminary data indicated that the fungus also colonized and killed tapioca scale (Aonidomytilus albus Cockerell) (Hemiptera: Diaspididae) and tobacco whitefly (Bemisia tabaci Gennadius) (Hemiptera: Aleyrodidae), a critical vector for many plant viral diseases. Mycosed cadavers of these eight targeted insects are shown in Figure 8.

In the infection of cassava mites, the legs were one of the most frequent sites for fungal colonization. It could be because the legs have a relatively higher density of spines or hair-like structures to anchor conidia than the insect body [28]. For M. robertsii ARSEF 2575 growing on the surface of Manduca sexta caterpillars, the conidia are growing along the cuticle and come across hair sockets, which trigger appressorium production. Hair sockets represent a zone of weakness in the cuticle, which the fungus can exploit [29].

For a successful host infection, fungal adhesion and conidial germination occur within $24 \mathrm{~h}$ after inoculation. Conidia of several entomopathogenic fungi have the characteristic outer layer. This layer is known as the rodlet later and consists of hydrophobin, the main protein for facilitating the adhesion to the hydrophobic epicuticle [2,30]. The surface properties of aerial conidia from entomopathogenic fungi had the rugose surfaces and were relatively hydrophobic, including those of various strains of B. bassiana and M. anisopliae [31], that of B. bassiana BCC 2660 [32], and that of Metarhizium sp. BCC 4849 in this study. The aerial conidia had varied hydrophobicities that reflected the adaptation of the surface properties to suit their particular habitats and target insects.

Penetration through the cuticle is also vital for fungal infection. The Metarhizium enzyme chymoelastase Pr1 has been implicated in cuticle degradation [33]. The authors also speculated M. anisopliae used up to $78 \%$ of protein synthesis to produce this crucial enzyme in the process of penetration. Entomopathogenic fungi also produce chitinases, proteases, and lipases to degrade various layers of the insect cuticle [34].

The fungus Metarhizium sp. BCC 4849 killed the insects $72 \mathrm{~h}$ after inoculation, and the mycelial extrusion happened between 96 and $120 \mathrm{~h}$ after inoculation in laboratory, similarly to the previous report of M. anisopliae [35]. The mycelial extrusion was present initially in the intersegmental areas and later in other areas, resulting in cuticle degradation along the whole body of the insect. Our study showed a large number of mycelia and conidia in the anal cavity and opisthosoma region. Rapid external hyphal development and conidiation of entomopathogenic fungi were observed on two-spotted spider mites under moist conditions [36]. In another study on B. bassiana and M. anisopliae infection of subterranean termite Heterotermes tenuis using SEM [35], the duration of infection phases ranged between 0 to $144 \mathrm{~h}$ PI. The comparative data also showed that penetration, colo- 
nization, and conidiogenesis phases were relatively faster for M. anisopliae than B. bassiana, leading to higher mortality of M. anisopliae-inoculated insects.

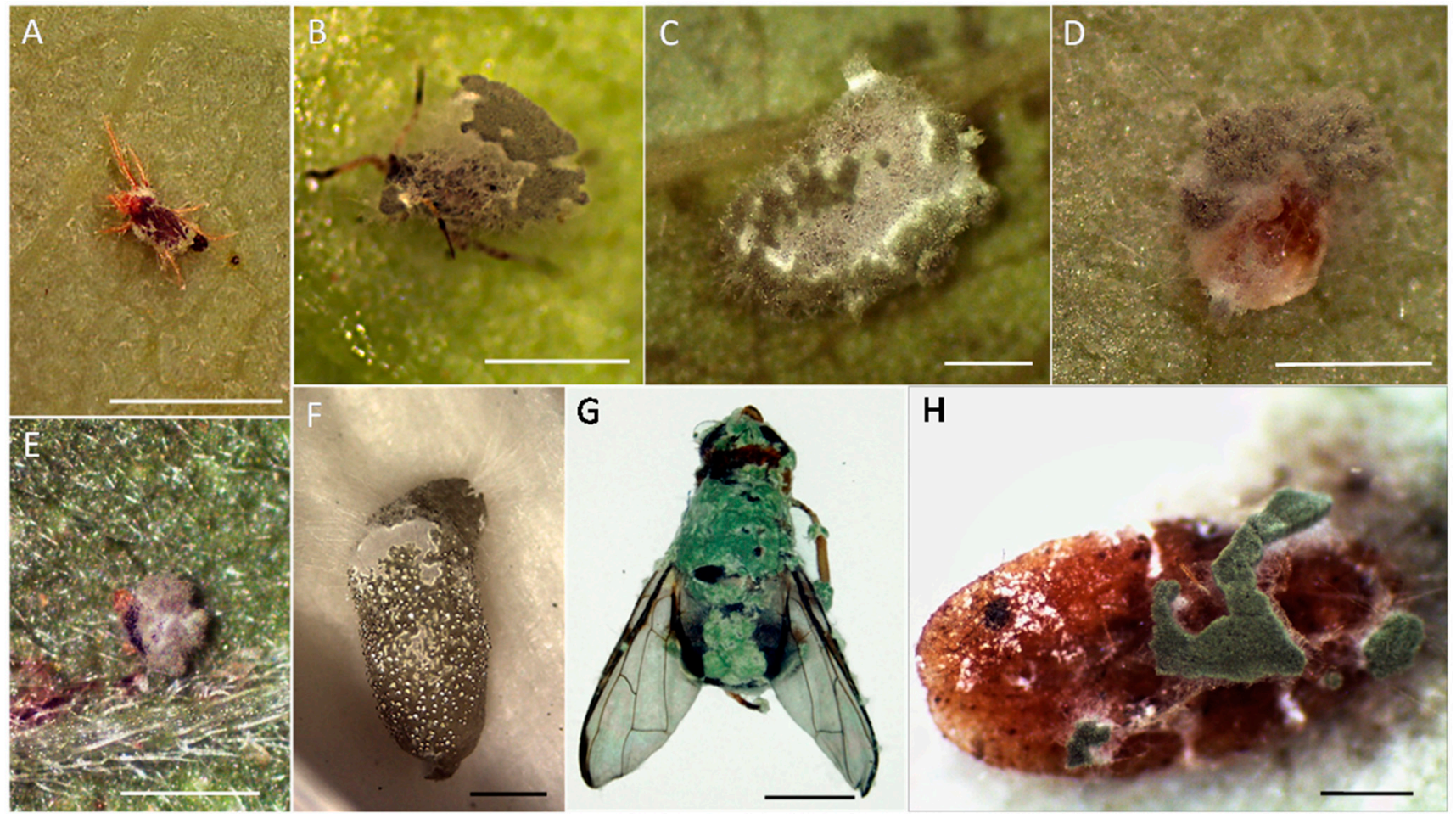

Figure 8. Abundant conidiation and mycelial formation of Metarhizium sp. BCC 4849 on various insect cadavers. (A) Cassava mite, Tetranychus truncates. (B) Bean aphid, Aphis craccivora. (C) Cassava mealybug, Phenacoccus manihoti. (D) Tobacco whitefly, Bemisia tabaci. (E) African mite, Eutetranychys africanus. (F) Sweet potato weevil larvae, Cylas formicarius. (G) Oriental fruit fly adult, Bactrocera dorsalis. (H) tapioca scale, Aonidomytilus albus. (A-E) Bars, 0.5 mm. (F-H) Bars, $2.0 \mathrm{~mm}$.

A limitation in the fungal application for insect/mite control is the lack of a suitable formulation or application strategies for a target host. Combined use of an entomopathogenic fungus with an insecticide/acaricide is an option worth exploring to control the pests. Integrated applications of higher and lower dosages of imidacloprid with $M$. anisopliae enhanced the mortality of subterranean burrowers [21]. Application of M. anisopliae in combination with one $\mu \mathrm{g}$ imidacloprid/g resulted in mortality of $88 \%$ of Cyrtomenus berg $i$ nymphs compared to $40 \%$ for the fungal application alone. In a study of interactions between five synthetic insecticides and five fungal strains, a combination of insecticides with B. bassiana and $M$. robertsii caused higher Rachiplusia $n u$ mortalities than any individual agents alone [37]. In our study, we used a combination of an entomopathogenic fungus with a diluted dose of synthetic acaricide. Our result showed that E. africanus population decreased dramatically after application for 4 days. The mite mortality was nearly $100 \%$ in 7 days post application. The lower dose of fenpyroximate enhanced the entomopathogen's efficacy, leading to the faster mycosis of cadavers.

Alves et al. (2002) [38] proposed a practical requirement for field application is minimal loss of viability after at least three months in storage at $30{ }^{\circ} \mathrm{C}$. However, if a storage of at least twelve months is required, cool storage would be necessary [39]. Among solid and liquid formulation of $M$. anisopliae stored at $30^{\circ} \mathrm{C}$, the solid formulations such as vermicompost, de-oiled castor cake, and farmyard manure formulations retained shelflife for 210, 190, and 160 days, respectively, compared to gypsum and talc powder that declined by 110 days under storage [40]. In this work, conidia formulated in kaolin-powder formulation and stored with the moisture-oxygen absorber (RP-3A) retained $>10^{8} \mathrm{CFU} \mathrm{g}^{-1}$ after four months (120 days) of storage at $35^{\circ} \mathrm{C}$. The revolutionary preservation (RP) system 
contains a technology capable of effectively absorbing moisture, oxygen, and corrosive gases even under dry conditions [41,42]. The RP is comprised of 5-15\% unsaturated organic compound, $10-45 \%$ calcium oxide, $10-50 \%$ mordenite, $5-15 \%$ activated carbon, and $10-30 \%$ polyethylene [43]. RP-3A sachets used in this study absorb both moisture and oxygen in a 300-mL air volume. This absorber extends conidia's shelf life by protecting fungal cells against degradation by oxidation and free water [42]. The effectiveness of RP oxygen and moisture absorbers for extending the shelf life of conidia of B. bassiana GHA was demonstrated at a high temperature of $40{ }^{\circ} \mathrm{C}$ for six months or at $50{ }^{\circ} \mathrm{C}$ for two months [42].

The desired characteristics of a competitive mycopesticide are efficacy comparable to its chemical counterpart, an ability to be used as a component of an IPM program, the stability of the product (long shelf life during transport and storage), low toxicity and ecotoxicity (compared to the chemical pesticide), and simplicity of production and application [44]. Our data indicate that Metarhizium sp. BCC 4849 is a promising mycoinsecticide. Its use combined with a lower dose of fenpyroximate is a potential candidate in IPM programs to control pests with pesticides and acaricides. Our findings on the infection processes add to the existing knowledge of how the fungus infects insect hosts. Nonetheless, this IPM strategy should be determined at a broad field level to verify its efficacy.

Author Contributions: Conceptualization, A.A., B.P., S.T., S.I., S.R., M.S. and M.T.; funding acquisition, A.A.; project administration, A.A. and R.W.; Writing-Original draft, R.W.; Writing-Review and Editing, A.A.; investigation, R.W., N.P., C.S. (Chettida Srisuksam), K.K. and T.H.; formal analysis, D.S., C.S. (Chutima Sonthirod), S.L. and S.R. All authors have read and agreed to the published version of the manuscript.

Funding: This research was supported by grants from the Research Development Innovation Management for National Strategic and Network Division (RNS) and BIOTEC, National Science and Technology Development Agency (NSTDA), Thailand.

Institutional Review Board Statement: Not applicable.

Informed Consent Statement: Not applicable.

Data Availability Statement: The data presented in this study are available in the manuscript.

Acknowledgments: We are grateful for access to the SEM system at the NSTDA Characterization and Testing Service Center (NCTC), Thailand. We thank Somruetai Jaiyen for help in insect biology and microscopy.

Conflicts of Interest: The authors declare no conflict of interest.

\section{References}

1. Faria, M.R.D.; Wraight, S.P. Mycoinsecticides and Mycoacaricides: A comprehensive list with worldwide coverage and international classification of formulation types. BioControl 2007, 43, 237-256. [CrossRef]

2. Ment, D.; Gindin, G.; Rot, A.; Soroker, V.; Glazer, I.; Barel, S.; Samish, M. Novel technique for quantifying adhesion of Metarhizium anisopliae conidia to the tick cuticle. Appl. Environ. Microbiol. 2010, 76, 3521-3528. [CrossRef] [PubMed]

3. Fasulo, T.R.; Denmark, H.A. Two spotted spider mite, Tetranychus urticae Koch. (Arachnida: Acari: Tetranychidae). EDIS 2003, 15, 1-5. [CrossRef]

4. Strickler, J. Growing potential, hemp could be game changer for American farmers. Acres USA 2018, 48, 22-26.

5. Palaniswami, M.S.P.; Pillai, K.S.; Nair, R.R.; Mohandas, C. A new cassava pest in India. Cassava Newslett. 1995, 9, 6-7.

6. Bernardo, E.; Esquevia, E. Seasonal abundance of the cassava red spider mite, Tetranychus kanzawai Kishida, and its predators on some cassava accessions. Ann. Trop. Res. 1981, 3, 197-203.

7. El-Sharabasy, H.M. Laboratory evaluation of the effect of the entomopathogenic fungi, Hirsutella thompsonii and Paecilomyces fumosoroseus against the citrus brown mite Eutetranychus orientalis (Acari: Tetranychidae). Plant Protect. Sci. 2016, 51, 39-45. [CrossRef]

8. Shternshis, M.; Andreeva, I.; Trandysheva, M. Effect of host plant on control of Tetranychus urticae by Verticillium (Lecanicillium) lecanii. IOBC/wprs Bull. 2005, 28, 37-40.

9. Wekesa, V.W.; Maniania, N.K.; Knapp, M.; Boga, H.I. Pathogenicity of Beauveria bassiana and Metarhizium anisopliae to the tobacco spider mite Tetranychus evansi. Exp. Appl. Acarol. 2005, 36, 41-50. [CrossRef]

10. Bugeme, D.M.; Maniania, N.K.; Knapp, M.; Boga, H.I. Effect of temperature on virulence of Beauveria bassiana and Metarhizium anisopliae isolates to Tetranychus evansi. Exp. Appl. Acarol. 2008, 46, 275-285. [CrossRef] 
11. Lord, J.C. From Metchnikoff to Monsanto and beyond: The path of microbial control. J. Invertebr. Pathol. 2005, 89, 19-29. [CrossRef]

12. Iwanicki, N.S.A.; Pereira, A.A.; Botelho, A.; Rezende, J.M.; Moral, R.A.; Zucchi, M.I.; Delalibera Junior, I. Monitoring of the field application of Metarhizium anisopliae in Brazil revealed high molecular diversity of Metarhizium spp in insects, soil and sugarcane roots. Sci. Rep. 2019, 9, 4443. [CrossRef]

13. Aw, K.M.S.; Hue, S.M. Mode of infection of Metarhizium spp. fungus and their potential as biological control agents. J. Fungi 2017, 3, 30. [CrossRef]

14. Leao, M.P.; Tiago, P.V.; Andreote, F.D.; de Araujo, W.L.; de Oliveira, N.T. Differential expression of the pr1A gene in Metarhizium anisopliae and Metarhizium acridum across different culture conditions and during pathogenesis. Genet. Mol. Biol. 2015, $38,86-92$. [CrossRef]

15. Ortiz-Urquiza, A.; Keyhani, N.O. Action on the surface: Entomopathogenic fungi versus the insect cuticle. Insects 2013, 4, 357-374. [CrossRef]

16. Butt, T.M.; Coates, C.J.; Dubovskiy, I.M.; Ratcliffe, N.A. Entomopathogenic fungi: New insights into host-pathogen interactions Adv. Genet. 2016, 94, 307-364. [CrossRef]

17. Gabarty, A.; Salem, H.M.; Fouda, M.A.; Abas, A.A.; Ibrahim, A.A. Pathogencity induced by the entomopathogenic fungi Beauveria bassiana and Metarhizium anisopliae in Agrotis ipsilon (Hufn.). J. Radiat. Res. Appl. Sci. 2019, 7, 95-100. [CrossRef]

18. St Leger, R.J.; Wang, J.B. Metarhizium: Jack of all trades, master of many. Open Biol. 2020, 10, 200307. [CrossRef]

19. Houndété, T.A.; Kétoh, G.K.; Hema, O.S.; Brévault, T.; Glitho, I.A.; Martin, T. Insecticide resistance in field populations of Bemisia tabaci (Hemiptera: Aleyrodidae) in West Africa. Pest Manag. Sci. 2010, 66, 1181-1185. [CrossRef]

20. Song, L.; Li, W.; Guo, H.; Wang, S.; Shen, H. Inheritance of resistance to abamectin+ pyridaben in Tetranychus truncatus Ehara Chin. J. Entomol. 2019, 56, 150-154. [CrossRef]

21. Jaramillo, J.; Borgemeister, C.; Ebssa, L.; Gaigl, A.; Tobón, R.; Zimmermann, G. Effect of combined applications of Metarhizium anisopliae (Metsch.) Sorokin (Deuteromycotina: Hyphomycetes) strain CIAT 224 and different dosages of imidacloprid on the subterranean burrower bug Cyrtomenus bergi Froeschner (Hemiptera: Cydnidae). Biol. Control 2005, 34, 12-20. [CrossRef]

22. Paula, A.R.; Carolino, A.T.; Paula, C.O.; Samuels, R.I. The combination of the entomopathogenic fungus Metarhizium anisopliae with the insecticide imidacloprid increases virulence against the dengue vector Aedes aegypti (Diptera: Culicidae). Parasit Vectors 2011, 4, 8. [CrossRef]

23. Jones, P.; Binns, D.; Chang, H.Y.; Fraser, M.; Li, W.; McAnulla, C.; McWilliam, H.; Maslen, J.; Mitchell, A.; Nuka, G.; et al InterProScan 5: Genome-scale protein function classification. Bioinformatics 2014, 30, 1236-1240. [CrossRef]

24. Ashburner, M.; Ball, C.A.; Blake, J.A.; Bostein, D.; Butler, H.; Cherry, J.M.; Davis, A.P.; Dolinski, K.; Dwight, S.S.; Eppig, J.T.; et al. Gene ontology: Tool for the unification of biology. Nat. Genet. 2000, 25, 9-25. [CrossRef]

25. Almagro Armenteros, J.J.; Tsirigos, K.D.; Sonderby, C.K.; Petersen, T.N.; Winther, O.; Brunak, S.; von Heijne, G.; Nielsen, H. SignalP 5.0 improves signal peptide predictions using deep neural networks. Nat. Biotechnol. 2019, 37, 420-423. [CrossRef]

26. Krogh, A.; Larsson, B.; von Heijne, G.; Sonnhammer, E.L. Predicting transmembrane protein topology with a hidden Markov model: Application to complete genomes. J. Mol. Biol. 2001, 305, 567-580. [CrossRef]

27. Hu, X.; Xiao, G.; Zheng, P.; Shang, Y.; Su, Y.; Zhang, X.; Liu, X.; Zhan, S.; Leger, R.J.S.; Wang, C. Trajectory and genomic determinants of fungal-pathogen speciation and host adaptation. PNAS 2014, 111, 16796-16801. [CrossRef]

28. Amnuaykanjanasin, A.; Jirakkakul, J.; Panyasiri, C.; Panyarakkit, P.; Nounurai, P.; Chantasingh, D.; Eurwilaichitr, L.; Cheevadhanarak, S.; Tanticharoen, M. Infection and colonization of tissues of the aphid Myzus persicae and cassava mealybug Phenacoccus manihoti by the fungus Beauveria bassiana. Biol. Control 2012, 58, 379-391. [CrossRef]

29. St Leger, R.J.; Roberts, D.W.; Staples, R.C. A Model to explain differentiation of appressoria by germlings of Metarhizium anisopliae. J. Invertebr. Pathol. 1991, 57, 299-310. [CrossRef]

30. Tseng, M.N.; Chung, C.L.; Tzean, S.S. Mechanisms relevant to the enhanced virulence of a dihydroxynaphthalene-melanin metabolically engineered entomopathogen. PLoS ONE 2014, 9, e90473. [CrossRef]

31. Jeffs, L.B.; Khachatourians, G.G. Estimation of spore hydrophobicity for members of the genera Beauveria, Metarhizium, and Tolypocladium by salt-mediated aggregation and sedimentation. Can. J. Microbiol. 1997, 43, 23-28. [CrossRef]

32. Udompaisarn, S.; Toopaang, W.; Sae-Ueng, U.; Srisuksam, C.; Wichienchote, N.; Wasuwan, R.; Nahar, N.A.S.; Tanticharoen, M.; Amnuaykanjanasin, A. The polyketide synthase PKS15 has a crucial role in cell wall formation in Beauveria bassiana. Sci. Rep. 2020, 10, 12630. [CrossRef] [PubMed]

33. St Leger, R.J.; Cooper, R.M.; Charnley, A.K. The Effect of melanization of Manduca sexta cuticle on growth and infection by Metarhizium anisopliae. J. Invertebr. Pathol. 1988, 52, 459-470. [CrossRef]

34. Charnley, A.K.; Leger, S.T. The Role of cuticle-degrading enzymes in fungal pathogenesis in insects. In The Fungal Spore and Disease Initiation in Plants and Animals; Cole, G.T., Hoch, H.C., Eds.; Springer: Boston, MA, USA, 1991; pp. 267-286.

35. Moino, A., Jr.; Alves, S.B.; Lopes, R.B.; Neves, P.M.O.J.; Pereira, R.M.; Vieira, S.A. External development of the entomopathogenic fungi Beauveria bassiana and Metarhizium anisopliae in the subterranean termite Heterotermes tenuis. Sci. Agric. 2002, 59, 267-273. [CrossRef]

36. Elhakim, E.; Mohamed, O.; Elazouni, I. Virulence and proteolytic activity of entomopathogenic fungi against the two-spotted spider mite, Tetranychus urticae Koch (Acari: Tetranychidae). Egypt. J. Biol. Pest Control 2020, 30, 30. [CrossRef] 
37. Pelizza, S.A.; Schalamuk, S.; Simon, M.R.; Stenglein, S.A.; Pacheco-Marino, S.G.; Scorsetti, A.C. Compatibility of chemical insecticides and entomopathogenic fungi for control of soybean defoliating pest, Rachiplusia nu. Rev. Argent. Microbiol. 2018, 50, 189-201. [CrossRef]

38. Alves, R.T.; Bateman, R.P.; Gunn, J.; Prior, C.; Leather, S.R. Effects of different formulations on viability and medium-term storage of Metarhizium anisopliae conidia. Neotrop. Entomol. 2002, 31, 91-99. [CrossRef]

39. Moore, D.; Douro-Kpindou, O.K.; Jenkins, N.E.; Lomer, C.J. Effects of moisture content and temperature on storage of Metarhizium flavoviride conidia. Biocontrol Sci. Technol. 2010, 6, 51-62. [CrossRef]

40. Bagwan, N.B. Mass multiplication and shelf-life of Metarhizium anisopliae and Beauveria bassiana in solid and liquid formulations. Int. J. Plant Prot. 2011, 4, 34-37.

41. Mascarin, G.M.; Jackson, M.A.; Behle, R.W.; Kobori, N.N.; Junior, I.D. Improved shelf life of dried Beauveria bassiana blastospores using convective drying and active packaging processes. Appl. Microbiol. Biotechnol. 2016, 100, 8359-8370. [CrossRef]

42. Faria, M.; Hotchkiss, J.H.; Wraight, S.P. Application of modified atmosphere packaging (gas flushing and active packaging) for extending the shelf life of Beauveria bassiana conidia at high temperatures. Biol. Control. 2012, 61, 78-88. [CrossRef]

43. Day, J. Practical application of the revolutionary preservation (RP) system for marcasite. In Proceedings of the 14th Triennial Meeting-ICOM Committee for Conservation, The Hague, The Netherlands, 12-16 September 2005.

44. Zaki, O.; Weekers, F.; Thonart, P.; Tesch, E.; Kuenemann, P.; Jacques, P. Limiting factors of mycopesticide development. Biol. Control 2020, 144, 104220. [CrossRef] 